\title{
Penanda Klausa Adverbial dalam Bahasa Angkola
}

The Markers of Adverbial Clauses in Angkola Language

\author{
Melani Rahmi Siagian \& Mulyadi \\ Fakultas Ilmu Budaya, Universitas Sumatera Utara
}

Pos-el: melanirahmi80@gmail.com, mulyadi.usu@gmail.com

Naskah Diterima Tanggal 24 Februari 2021—Direvisi Akhir Tanggal 05 Desember 2021—Disetujui Tanggal 10 Desember 2021

\begin{abstract}
Abstrak
Klausa adverbial adalah klausa subordinat yang berfungsi memberikan keterangan klausa utama. Kehadiran klausa adverbial tidak menjadi keharusan, tetapi dapat membantu menciptakan koherensi sebuah wacana. Penelitian ini bertujuan untuk mendeskrpsikan penanda klausa adverbial dalam Bahasa Angkola. Metode yang digunakan adalah deskriptif kualitatif. Pengumpulan data dilakukan dengan metode cakap, simak, dan catat. Data dalam penelitian ini adalah klausa adverbial dalam Bahasa Angkola yang diperoleh dari penutur asli Bahasa Angkola dan juga sumber tertulis yang didapatkan dari buku berbahasa Angkola. Analisis data dilakukan dengan mencocokkan data dengan teori yang terdapat dalam penelitian yaitu penanda klausa adverbial dalam kalimat Bahasa Angkola. Hasil penelitian menunjukkan terdapat lima tipe klausa adverbial dalam Bahasa Angkola, yaitu klausa temporal (temporal clause) yang ditandai dengan kata dung 'setelah' serta dompak 'ketika', klausa bersyarat (conditional clause) yang ditandai dengan kata molo ' kalau', klausa kausal (causal clause) yang ditandai dengan kata harana 'karena', klausa tujuan (purposal clause) yang ditandai dengan kata anso 'agar/supaya', serta klausa konsesi (consessive clause) yang ditandai dengan kata bope 'walaupun'dan aha pe 'apa pun'. Penggunaan kluasa adverbial dapat ditemukan pada posisi inisial ataupun final dalam sebuah kalimat.
\end{abstract}

Kata Kunci: klausa adverbial, Bahasa Angkola, strategi pemarkahan.

\begin{abstract}
An adverbial clause is a subordinate clause that serves to provide information on the main clause. The presence of an adverbial clause is not a must, but it can help create coherence in a discourse. This study aims to describe the markers of adverbial clauses in Angkola language. The method used is descriptive qualitative markers. Data collections are conducted by speaking, listening, and taking notes. The data in this study are adverbial clauses in Angkola language obtained from native Angkola speakers and also written sources obtained from Angkola language books. Data analysis was carried out by matching the data with the theory contained in the study, namely adverbial clause markers in Angkola language sentences. The results showed that there were five types of adverbial clauses in Angkola language, namely temporal clauses marked by the word dung 'after' and dompak 'when', conditional clauses marked by the word molo 'if', causal clauses (causal clause) which is marked by the word harana 'because', the purpose clause (purposal clause) which is marked by the word anso 'so that/so', and the concession clause (consessive clause) which is marked by the words bope 'although' and aha pe 'what ever'. The use of adverbial clauses can be found at the initial or final position in a sentence.
\end{abstract}

Keywords: adverbial clause, Angkola language, marking strategy. 


\section{PENDAHULUAN}

Bahasa Angkola (BA) adalah salah satu subbahasa Batak, selain Toba, Simalungun, Mandailing, Karo, dan Pakpak. Orang Angkola mayoritas mendiami beberapa kabupaten di Sumatera Utara, yaitu Kabupaten Tapanuli Selatan, Kabupaten Padang Lawas, serta Kabupaten Padang Lawas Utara. Sebagai sebuah bahasa, BA juga mempunyai sistem tata bahasa selayaknya bahasa lain yang ada di dunia, salah satunya adalah penggunaan klausa adverbial atau biasa disebut juga dengan klausa keterangan.

Kata keterangan tidak dapat berdiri sendiri dalam kalimat, melainkan harus berdampingan dengan kata lain untuk mewujudkan kesatuan makna. Chaer (2015) menyatakan bahwa Adverbia atau kata keterangan merupakan kategori yang mendampingi nomina, verba, dan adjektiva dalam pembentukan frase atau dalam pembentukan sebuah klausa (hlm. 49). Alwi dkk. (2003) menyampaikan bahwa dalam tataran klausa, adverbial mewatasi atau menjelaskan fungsi-fungsi sintaksis (hlm. 197).

Sementara itu, klausa adverbial merupakan salah satu klausa dependen atau subordinat di dalam tata bahasa tradisional yang berfungsi sebagai adverbia, selain klausa relatif dan pelengkap. Kortman B. (2001) mengatakan ketiga klausa tersebut berfungsi sebagai adverbial yang memberikan informasi tentang keadaan temporal, lokatif, kausal, kondisional dll. dari keadaan yang digambarkan dalam klausa utama. Klausa adverbial disebut sebagai klausa subordinat karena klausa tersebut melekat pada klausa yang lebih tinggi yaitu klausa utama.
Thomson dan Longacre (1985)

mengatakan klausa adverbial dapat ditemukan pada semua bahasa di dunia, walaupun tidak ditandai dengan cara yang sama. Bentuk yang paling umum adalah penanda if 'jika', because 'karena' atau when 'ketika' yang biasanya banyak terdapat pada bahasa Indoeropa.

Pembahasan mengenai klausa adverbial umumnya mengacu pada kaidah bahasa Inggris atau bahasa dari barat lainnya. Sehingga, menjadi hal yang menarik untuk dikaji pada bahasa-bahasa yang lainnya, termasuk bahasa daerah yang ada di Indonesia.

Topik mengenai klausa adverbial pernah ditulis oleh Mc Garry Theresa dan Kiser Kelsey (2016). Dalam studi ini peneliti menganalisis dialog dalam drama Shakespear dalam kaitannya dengan penggunaan klausa adverbial. Temuan dalam penelitian ini adalah penggunaan klausa tujuan (purposal clause) lebih banyak digunakan dalam cerita sejarah dan klausa bersyarat dalam cerita komedi. Selanjutnya, karakter wanita dan pria berbicara sangat mirip dalam kaitannya dengan sintaksis. Selain itu, Artawa dkk. (2018) dalam tulisannya mendeskripsikan bentuk-bentuk klausa adverbial temporal dalam bahasa Bali, seperti dugas 'kapan', sasuba 'setelah', satonden 'sebelum', dan penanda-penanda ini muncul di awal klausa, karena Bahasa Bali merupakan kepala akhir. Selanjutnya, Markhamah (2019), dalam penelitiannya mendeskripsikan bentuk adverbia penanda modalitas dalam teks terjemahan alquran. Dalam tulisan ini dijelaskan spesifikasi penggunaan adverbia dalam ragam teks terjemahan alquran. Seperti penanda modalitas kepastian yang ditandai dengan 
'pasti', 'menang', penanda modalitas kesungguhan ditandai dengan 'sungguh'. Penanda modalitas dalam bentuk turunan meliputi bentuk ulang, berimbuhan, gabungan, serta berpartikel. Kategori yang dimodifikatori adalah adjektiva, nomina, verba, frasa preposisi, dan kata petunjuk. Di dalam penelitian ini juga dideskripsikan bentuk adverbia dalam bentuk kata, frasa dan klausa.

Tulisan yang berkaitan dengan BA juga sudah banyak dilakukan, di antaranya adalah penelitian Siregar (2020) yang memaparkan konstruksi gramatikal Bahasa Angkola dan menerangkan bahwa yang menjadi ciri dari BA adalah adanya prototipe urutan kata yang memiliki kesamaan pola dengan VOS, contoh: manjalaki bayo ia 'dia mencari pria'. Selanjutnya, penelitian yang dilakukan Nasution dan Mulyadi (2020) tentang konstruksi predikat kompleks dalam BA. Karakteristik predikat kompleks dalam BA adalah pembentukan frasa/kalimat yang terdiri atas dua verba atau lebih, letaknya berdampingan, dan memiliki kesamaan aspek dan negasi. Lubis dan Mulyadi (2020) menulis konstruksi pasif bahasa Angkola yang dianalisis dengan teori $\mathrm{X}$ Bar. Dari beberapa hasil penelitian di atas belum ditemukan penelitian mengenai klausa adverbial dalam BA.

Berdasarkan uraian singkat pada pendahuluan diatas, yang menjadi permasalahan dalam penelitian ini adalah pengungkapan bentuk klausa adverbial dalam BA. Penelitian ini dilaksanakan dengan tujuan untuk mendeskripsikan ragam penanda klausa adverbial dalam BA yang dikaitkan dengan penggunaanya dalam kalimat.

\section{LANDASAN TEORI}

\section{Klausa Adverbial}

Seperti halnya kata keterangan yang merupakan kata atau frasa tunggal, klausa adverbial juga dikategorikan sesuai dengan peran semantiknya. Sebagai sebuah klausa subordinat, klausa adverbial bergantung pada klausa lain dan membentuk satu kesatuan makna. Menurut Thomson et al. (2007), bagaimanapun klausa keterangan dipandang sebagai klausa hipotaktis yang digabungkan dengan klausa utama karena klausa keterangan berhubungan dengan klausa utama secara keseluruhan.

Thomson et. al. (2007) juga mengatakan bahwa pada dasarnya klausa subordinat terbagi atas tiga bagian, yaitu, klausa pelengkap yang berfungsi sebagai frasa kata benda, klausa relatif yang berfungsi sebagai pengubah kata benda, selanjutnya yang terakhir adalah klausa adverbial yang berfungsi sebagai pengubah frasa kerja atau klausa keseluruhan. Lehman dalam Diesel (2001) selanjutnya menyatakan bahwa klausa adverbial ditandai oleh subordinator adverbia, sedangkan klausa relatif ditandai kata benda.

Keberadaan klausa adverbial di dalam sebuah kalimat bukan hal yang wajib, sesuai dengan fungsinya yaitu memberikan keterangan dari klausa utamanya, namun apabila dihilangkan keterangan tersebut tidak mengurangi makna inti pada klausa utamanya. Thomson (2007) dan Diesel (2013) mempunyai pendapat yang sama yaitu klausa keterangan membantu menciptakan wacana yang koheren. Hal senada juga disampaikan Kridalaksna (1986) bahwa adverbia berfungsi untuk tekanan makna, 
memperjelas, memantapkan kategori yang didampinginya, serta menerangkan seluruh kalimat. Selanjutnya menurut Diesel (2001), klausa adverbial adalah pengubah klausa utama dan dengan demikian keberadaanya menjadi opsional, sedangkan klausa relatif sebagai pengubah kata benda atau frasa keberadaanya juga opsional, sedangkan klausa pelengkap yang merupakan argumen inti dari sebuah predikat keberadaanya tidak dapat dihilangkan.

Sesuai dengan perannya sebagai klausa pendukung, klausa adverbial berfungsi untuk menambahkan informasi klausa utama, baik informasi waktu, tempat, sebab akibat, dsb. Hal ini sesuai dengan pendapat Lin (2015) yang menyatakan bahwa fungsi utama klausa adverbial adalah sebagai informasi tentang keadaan temporal, lokatif, kausal, bersyarat yang digambarkan pada klausa utama.

Menurut Kortman, B. (2001), untuk menghasilkan makna yang koheren, klausa adverbial dapat diletakkan di awal untuk mendahului klausa utama, atau di posisi akhir untuk mengikuti klausa utama. Klausa adverbial yang muncul lebih dulu dalam kalimat berfungsi sebagai penjelas untuk informasi yang akan datang, selanjutnya dapat juga berfungsi sebagai penghubung kembali akan peristiwa pada kalimat, wacana, atau paragraf yang terjadi sebelumnya. Selain itu, klausa adverbial juga berfungsi sebagai penyedia informasi mengenai latar belakang sebuah kalimat kompleks atau wacana. Sementara itu, klausa adverbial yang muncul mengikuti klausa utama, ruang lingkup fungsinya menjadi lebih kecil, yaitu hanya menerangkan apa yang terjadi pada klausa yang muncul sebelumnya.

Lin (2015) juga mengungkapkan bahwa terdapat perbedaan dalam hal pendistribusian klausa adverbial dalam kalimat yang dikaitkan dengan hubungan semantiknya dengan klausa utama. Diesel (2013) dan Hatterle (2011) menemukan bahwa klausa bersyarat lebih sering muncul sebagai klausa adverbial inisial yang muncul sebelum klausa inti, klausa temporal mempunyai ciri kemunculan yang bervariasi baik sebelum ataupun sesudah klausa inti, sedangkan klausa adverbial final adalah lebih sering ditempati oleh klausa kausal dan tujuan.

Thomson, et. al. (2007), menerangkan bahwa ada tiga perangkat yang biasanya ditemukan untuk menandai klausa subordinat, ketiga jenis penandaan ini juga digunakan untuk menandai klausa adverbial, yaitu: (a) morfem subordinat, (b) bentuk kata kerja khusus, (c) urutan kata. Klausa adverbia BA ditandai dengan morfem subordinat, seperti anso 'agar', harana 'karena', muda 'kalau'. Tandatanda ini muncul sebelum klausa utama, namun tidak menutup kemungkinan muncul pada kluasa adverbial final.

Kortman, B. (2001), Thomson et.all. (2007) membagi jenis klausa adverbial menjadi beberapa tipe, yaitu:

1. Klausa adverbial temporal (temporal clause), yang berkaitan dengan waktu atau durasi. Beberapa ciri kata yang terdapat dalam klausa temporal adalah kata when 'ketika', after 'sesudah', before 'sebelum', once 'sekali', until 'sampai', as soon as 'segera', as long as 'selama'.

Contoh: we'll go when Tom gets here. 
'Kami akan pergi ketika Tom sampai di sini'.

2. Klausa bersyarat (conditional clause) yang ditandai dengan if ' jika'.

Contoh: If we are study hard, we can get the best score.

'Jika kita belajar keras, kita akan mendapatkan nilai terbaik'.

3. Klausa kausal (causal clauses) yang ditandai oleh because, dan since 'karena'.

Contoh: You have to wash the shoes, cause it's dirty.

'Kamu harus mencuci sepatu itu, karena kotor'.

4. Klausa tujuan (purposal clauses) yang ditandai dengan so, so that, dan in order that.

Contoh: I'll finish the task today, so I will have more spare time.

'Saya akan menyiapkan tugas hari ini, sehingga saya mempunyai lebih banyak waktu luang'.

5. Klausa konsesi (Concessive Clause) ditandai oleh though, although, even though, atau even if.

Contoh: Although it was rain, the basket ball match kept going on.

'Walaupun hujan, pertandingan basket itu terus berjalan'.

Concessive clause adalah klausa untuk membuat konsesi. Ciri yang paling umum pada klausa ini adalah bentuk pertentangan antara klausa utama dan klausa pendukung. Terdapat dua jenis klausa konsesi, yaitu klausa konsesi yang pasti dan yang tak terbatas. Dalam Bahasa Inggris, klausa konsesi dengan label pasti ditandai dengan kata although 'meskipun'. Sebaliknya, klausa konsesi tidak terbatas ditandai dengan kata no matter what 'tidak peduli apa' dan whatever 'apa pun'.

\section{METODE PENELITIAN}

Penelitian ini merupakan penelitian deskriptif kualitatif. Sutopo (2002) menyatakan bahwa penelitian deskripsi kualitatif adalah penelitian yang dilakukan dengan cara mendeskripsikan sesuatu secara detail dan utuh sesuai keadaan sebenarnya di lapangan (hlm. 111).

Penelitian ini berupaya mengkaji pola penanda klausa adverbial pada BA. Pengumpulan data dilakukan dengan metode cakap, simak, dan catat untuk mendokumentasikan BA. Metode simak digunakan ketika mewawancarai penutur asli BA, selanjutnya data dicatat dan dipilah sesuai kategori yang diinginkan. Penulis memilih penutur asli BA yang berada di Medan. Penulis memilih dua orang penutur asli yang mempunyai pengetahuan serta mampu menggunakan BA dengan baik. Untuk melengkapi data, penulis juga menggunakan sumber tertulis yaitu buku adat yang berjudul "Horja, Adat Istiadat Dalihan Natolu" (1993) yang merupakan hasil Musyawarah Adat Parsadaan Marga Harahap dohot Anakboruna di Padangsidimpuan, 26-27 Desember 1991 serta buku yang berjudul "Pundjut-pundjutan" (1962) yang ditulis oleh B.M. Marpaung dan B.R. Sohuturon, buku ini merupakan buku peribahasa berbahasa Angkola.

Analisis data dalam penelitian menggunakan analisis deskriptif, yaitu dengan menjabarkan data yang ditemukan dan dicocokkan dengan teori yang terdapat dalam penelitian, yaitu penanda klausa adverbial dalam kalimat yang ada pada sumber data. 


\section{PEMBAHASAN}

Klausa adverbial dalam BA diwujudkan dalam bentuk klausa bawahan yang berfungsi untuk mendukung makna klausa yang lebih luas, yaitu klausa utama. Terdapat lima tipe klausa adverbial dalam BA sesuai dengan makna semantisnya yang ditunjukkan dengan penanda adverbia. Penanda yang berbeda akan membawa fungsi semantik yang berbeda pula.

Data berikut adalah kalimat yang terdiri atas dua klausa yang menujukkan klausa adverbial dengan fungsi penunjukan waktu atau yang disebut dengan klausa temporal (temporal clauses). Klausa tersebut dapat ditunjukkan dengan menggunakan penanda kata dung 'setelah' serta dompak 'ketika'.

1a. Dung kehe au tu poken, ia pe marangkat tu Medan.

Setelah aku pergi ke pasar, dia pun berangkat ke Medan.

1b. Ia pe marangkat tu Medan, dung kehe au tu poken.

Dia pun berangkat ke Medan setelah saya pergi ke pasar.

2a. Dompak mardahan Uma, ro Ayah san kantor.

Ketika Ibu memasak, Ayah datang dari kantor.

2b. Ro Ayah san kantor, dompak mardahan Uma.

Ayah datang dari kantor ketika Ibu memasak.

Fungsi semantik kata keterangan temporal pada data 1a dan $1 \mathrm{~b}$ menunjukkan urutan temporal, sedangkan pada data $2 \mathrm{a}$ dan $2 \mathrm{~b}$ memperlihatkan lokasi temporal. Data la dung kehe Au tu poken, Ia pe marangkat tu Medan, menyatakan urutan kegiatan, kegiatan marangkat 'berangkat' terjadi setelah peristiwa sebelumnya yaitu kehe 'pergi. Data 2a dan 2b menunjukkan lokasi temporal, bahwa peristiwa kegiatan berlangsung di lokasi waktu yang bersamaan. Peristiwa dompak mardahan umak 'ketika ibu memasak' berlangsung di lokasi waktu yang sama dengan klausa ro ayah san kantor 'ayah datang dari kantor'.

Contoh kalimat 1a, 1b, 2a, dan 2b di atas menunjukkan bahwa posisi klausa subordinat bisa diletakkan di posisi awal ataupun pada posisi final dalam kalimat. Apabila posisi klausa subordinat dibalik dan diletakkan pada posisi akhir maknanya tidak akan berubah, seperti yang terlihat pada data 1a dan 1b. Begitu juga yang terlihat pada data $2 \mathrm{a}$ dan $2 \mathrm{~b}$.

Selanjutnya, apabila subjek yang terdapat pada klausa subordinat berbeda dengan subjek yang ada pada klausa ordinat, maka posisinya bisa dipertukarkan. Posisi klausa subordinat yang menggunakan adverbial temporal dapat menduduki posisi awal untuk mengikuti klausa ordinat, namun juga bisa diposisikan di bagian akhir untuk mengikuti klausa utama.

3a. Lokot kehe tu sikola, dung mulak sian marbabo i saba.

Lokot pergi ke sekolah setelah pulang dari membersihkan rumput di sawah.

3b. Dung mulak sian marbabo saba, Lokot kehe tu sikola.

Setelah pulang dari membersihkan rumput di sawah, Lokot pergi ke sekolah.

Data 3a di atas terdiri atas dua klausa dengan subjek yang sama yaitu Lokot kehe tu sikola 'Lokot pergi ke sekolah' sebagai klausa utama, dan klausa temporal yaitu dung mulak sian marbabo $i$ saba 'setelah pulang dari membersihkan 
rumput di sawah'. Apabila subjek pada klausa ordinat dan klausa subordinat sama, subjek pada klausa subordinat dapat dihilangkan. Untuk konstruksi kalimat seperti itu, posisi klausa subordinat dapat dipertukarkan dengan klausa utama karena tidak akan mengubah makna, seperti telihat dalam data $3 b$.

Data 4 dan 5 menunjukkan jenis klausa adverbial bersyarat atau disebut juga dengan conditional clause. Klausa ini terjadi atas dasar hubungan satu sama lain di dalam kalimat. Dalam bahasa Inggris, untuk menyatakan struktur kalimat kondisional digunakan kata if 'jika' di dalam klausa subordinat dan kata then 'kemudian' untuk klausa utama. Data 4 merupakan contoh kalimat dalam BA yang menggunakan klausa adverbial bersyarat dengan penanda kata molo 'jika'. Klausa bersyarat menggunakan istilah kondisional tidak nyata yaitu situasi yang meramalkan apa yang mungkin terjadi. Ringgas-ringgas ma ho marsiajar 'rajin-rajinlah kau belajar' merupakan kalimat inti dengan makna prediksi akan hal yang terjadi berikutnya dalam klausa subordinat, yaitu molo por rohamu jadi halak na sonang 'jika hendak jadi orang yang senang'.

4. Ringgas-ringgas ma ho marsiajar, molo por rohamu jadi halak na sonang. 'Rajin-rajinlah kau belajar jika hendak jadi orang yang senang'

Sedangkan dalam data 5 , penanda klausa sintaksis kondisional bersyarat yang menjadi relevansi umum. Penanda sintaksis kondisonal dengan menggunakan morfem subordinat seperti molo 'jika/kalau' digunakan sebagai syarat kondisinal yang nyata akan apa yang terjadi pada peristiwa selanjutnya. Hal tersebut termasuk merujuk kepada kebiasaan umum yang terjadi di masyarakat. Contoh kalimat dalam data 5 diambil dari buku yang berjudul PundjutPundjutan (1962). Molo tinggal ibana di sanga inganan sanga sada luat 'kalau kita bermukim di suatu kampung' termasuk klausa adverbial bersyarat yang merupakan syarat kondisional yang diletakkan di awal kalimat untuk mendukung kalimat matriks berikutnya yang merupakan inti kalimat angkon niihutkon adat dohot ugari ni halan di luat $i$ ' harus kita ikuti adat dan budaya di kampung tersebut'.

5. Molo tinggal ibana di sanga inganan sanga sada luat, angkon niihutkon adat dohot ugari ni halak di luat i.

Kalau kita bermukim di suatu kampung, harus kita ikuti adat dan budaya di kampung tersebut.

Data 6 dan 7 menunjukkan klausa keterangan (causal clauses) yang menunjukkan proses sebab akibat yang ditandai dengan adverbia harana 'karena'.

6. Na kehe ia tu sikola, harana marnyae pamatang ia.

Dia tidak pergi ke sekolah, karena perutnya sakit.

7. Harana udan sajo sian manyogot, na bisa ia kehe tu saba.

Karena hujan saja sejak pagi, ia tidak bisa pergi ke sawah.

Klausa adverbial yang menunjukkan sebab akibat dalam studi tipologi adalah untuk mengekspresikan asosiasi semantik yang menunjukkan maksud, penyebab dan alasan. Klausa adverbial dalam bentuk sebab akibat sering menunjukkan bentuk negasi, seperti terlihat dalam data 6 dan 7 di atas. Hadirnya konstituen negatif dalam data 6 dan 7 menghasilkan bentuk peniadaan yang ditunjukkan dengan kata $n a$ 'tidak' 
sebagai akibat. Pengungkapan bentuk sebab dalam klausa subordinat ditandai dengan kata harana 'karena'. Penggunaan klausa subordinat tersebut dapat muncul di akhir mengikuti klausa utama, atau bisa juga muncul di awal sebagai pengantar sebelum klausa inti di dalam kalimat.

8. Angkon ringgas do hita marsiajar, anso manaek kelas.

Kita harus tekun belajar, agar naik kelas.

9. Anso ulang tarlambat, tibu hita marangkat acogot.

Supaya tidak terlambat, kita berangkat lebih awal besok.

Data 8 dan 9 menunjukkan penggunaan klausa adverbial tujuan yang disebut juga dengan purposal clause. Klausa tujuan menunjukkan niat agen untuk membawa peristiwa lain. Klausa tujuan berfungsi menghubungkan dua peristiwa, peristiwa pertama dilakukan untuk mencapai tujuan yang digambarkan pada peristiwa kedua. Posisi klausa subordinat dapat muncul di awal untuk menerangkan kalimat utama, namun juga dapat muncul pada posisi setelah klausa utama. Tidak ada perbedaan makna apabila posisi klausa subordinat diganti dengan klausa utama, begitu juga sebaliknya. Seperti yang terlihat dalam data 8, peristiwa awal yaitu angkon ringgas hita marsiajar 'kita harus tekun belajar' merupakan niat agen untuk mencapai klausa tujuan yaitu anso manaek kelas 'agar naik kelas'. Peristiwa awal merupakan klausa utama yang didukung oleh peristiwa selanjutnya untuk mendukung makna pada klausa utama.

Begitu juga halnya dengan data 9 , posisi klausa matriks tibu hita marangkat acogot 'kita berangkat lebih awal besok' yang berada pada urutan kedua setelah klausa subordinat, anso ulang terlambat 'supaya jangan terlambat' merupakan klausa ordinat yang merupakan tujuan dari tindakan pada klausa sebelumnya.

10. Bope por udan, ia totop kehe tu sikola. Walaupun hujan deras, ia tetap pergi ke sekolah.

11. Aha pe na didokkon ia, au inda porcaya.

Apa pun yang ia katakan, aku tidak percaya.

Data 10 dan 11 menunjukkan jenis

klausa konsesi (concessive clauses). Klausa konsesi adalah klausa yang menggambarkan pertentangan antara klausa subordinat dan klausa utama. Terdapat dua macam tipe klausa konsesi dalam BA, yaitu klausa konsesi dengan label pasti yang ditandai dengan kata bope 'walaupun' dan klausa konsesi tidak terbatas yang ditandai dengan kata aha pe 'apa pun'. Klausa adverbial dalam bentuk konsesi muncul di awal kalimat untuk menguatkan makna yang terdapat pada kalimat utama.

\section{PENUTUP}

Berdasarkan uraian pembahasan di atas, terdapat lima tipe penanda klausa adverbial dalam Bahasa Angkola (BA), yaitu:

1. Klausa yang berkaitan dengan waktu yang disebut dengan klausa temporal (temporal clause), di antaranya ditandai dengan kata dung 'setelah' dan dompak 'ketika'.

2. Klausa bersyarat (conditional clause), yang menjadi penanda dalam klausa ini adalah kata molo 'kalau'. 
3. Klausa kausal (causal clause) yang berkaitan dengan hubungan sebab akibat, penanda dalam klausa ini adalah kata harana 'karena'.

4. Klausa tujuan (purposive clause), ditandai dengan penanda anso 'supaya'

5. Klausa konsesi (concessive clause) terbagi dua yaitu klausa konsesi dengan label pasti yang ditandai dengan kata bope 'walaupun' dan klausa konsesi tidak terbatas yang ditandai dengan kata aha pe 'apa pun'.

Konstruksi penggunaan klausa adverbial dalam Bahasa Angkola dapat muncul pada posisi inisial dan juga final dalam kalimat. Beberapa tipe klausa adverbial tidak menimbulkan arti yang berbeda apabila posisinya dipertukarkan dari poisisi awal ke posisi final, namun ada sebagian tipe klausa adverbial yang hanya bisa diletakkan pada posisi tertentu tanpa bisa dipertukarkan.

\section{DAFTAR PUSTAKA}

Alwi, H, dkk. (2000). Tata Bahasa Baku Bahasa Indonesia. Edisi Ketiga (Cetakan Ketiga). Jakarta: PT Balai Pustaka (Persero).

Artawa, Ketut, et al. (2018). Temporal Adverbial Clause Marking in Balinese. Macrothink Institute: International Journal Of Linguistics, Vol. 10, No. 2.

Chaer, Abdul. (2015). Sintaksis Bahasa Indonesia. Jakarta: Rineka Cipta

Diessel, H. (2001). The Ordering Distribution of Main and Adberbial Clauses: a Typological Study. Language.77:433-455

Diessel, H. (2005). Competing Motivation for The Ordering of Main and Adverbial Clauses. Linguistic. 43, 449-470.
Parsadaan Marga Harahap dohot Anakboruna. (1993). Horja, Adat Istiadat Dalihan Natolu. Bandung: PT. Grafitri.

Kortman, B. (2001). Adverbial Clauses. International Encyclopedia of The Social and Behavioral Sciences (pp. 162-167). Pergamon.

Kridalaksana, H. (1986). Kelas Kata dalam Bahasa Indonesia. Jakarta: Gramedia Pustaka Utama.

Lin, Jing Xia. 2015. Adverbial Clauses in: James. D. Wright (Editor-in-Chief). International Encyclopedia of The Social and Behavioral Sciences, $2^{\text {nd }}$ Edition, Vol. 1, Oxford: Elsevier.pp. $185-188$

Lubis, I. S., Mulyadi. (2020). Emotional Verbs in Angkola Mandailing Language: A Natural Semantic Metalanguage Approach. Language Literacy: Journal of Lingistics, Literature, and Language Teaching, Vol. 14, No. 1, pp. 153-159.

Lyons, J. (1971). Introduction to Theoretical Linguistics. New York: Cambridge University Press.

Markhamah, M. W. (2019). Makna Adverbia Penanda Aspek, Sangkalan, dan Jumlah Pada Teks Terjemahan Alquran (TTA). The $1^{\text {st }}$ International Confrence on Lenguage, Literature, and Teaching. McGarry, Theresa, Kiser Kelsey. (2017). Adverbial Clauses and Speaker and Interlocutor Gender in Shakespear's Plays. Palgrave Communications.

Nasution, Latifah Yusri, Mulyadi. (2020). Predikat Kompleks Bahasa Angkola Mandailing. Jurnal Litera, vol. 19, No. 1.

Marpaung, B.M., Sohuturon, B.R. (1962). Pundjut-pundjutan. Medan: Islamiyah.

Siregar, E. B. A., Mulyadi. (2020). Typology and Grammatical Alignment of Angkola Language. 
Technium Social Sciences Journal, vol. 19. $641-650$.

Sutopo, H. B. (2002). Metodologi Penelitian Kualitatif: Teori dan Aplikasinya dalam Penelitian. Surakarta: Sebelas Maret University Press.

Thomson, Sandra A. Robert E.L., Shin J.J.H. (2007). Adverbial Clauses. In Timothy Shopen, ed, Language
Typology and Syntactic Description Second Edition. Cambridge: Cambridge University Press 237300.

Thomson, Sandra A. (1985). Grammar and Written Discourse. Initial and Final Purpose Clauses in English. In Quantified Studies in Discourse. 